\title{
Consumo e digestibilidade em ovinos alimentados com dietas contendo grão de milho moído, inteiro ou tratado com uréia, com três níveis de concentrado
}

\author{
Food intake and digestibility by sheep fed diets containing ground, whole or urea treated whole corn \\ grains at three concentrate levels
}

\begin{abstract}
Ivonir Taschetto Bolzan' Luis Maria Bonnnecarrère Sanchez ${ }^{\text {II }}$ Paulo Afonso Carvalho ${ }^{\text {III }}$ João Pedro Velho ${ }^{\text {IV }}$ Lisiane Dorneles de Lima ${ }^{I I I}$ Juciléia Morais $^{\text {I }}$ Rui Luiz Cadorin Jr. ${ }^{\text {III }}$
\end{abstract}

\section{RESUMO}

Este estudo foi conduzido usando grão de milho moído, inteiro ou inteiro tratado com uréia, na preparação de dietas contendo 30; 50 ou $70 \%$ de concentrado. Foram usados 18 cordeiros castrados, com $34,48 \mathrm{~kg}$ de peso vivo médio, distribuídos aleatoriamente nos tratamentos, durante três períodos experimentais, para medir-se o consumo e a digestibilidade dos constituintes da matéria seca da dieta. $O$ consumo de matéria seca (CMS), o consumo de proteína bruta $(C P B)$ e o consumo de fibra em detergente neutro (CFDN) não foram afetados $(P>0,05)$ pelo tratamento do grão de milho. Entretanto, o nível de inclusão de concentrado afetou $(P<0,05)$ o CMS e o CPB, ocasionando incrementos do consumo até os níveis de 55,50 e 58,75\% de concentrado, respectivamente. O CFDN decresceu linearmente $(P<0,05)$ em função do aumento do nível de concentrado. As dietas elaboradas com grão de milho inteiro tratado com uréia apresentaram maior digestibilidade aparente da proteína bruta. Todavia, a digestibilidade dos demais constituintes da matéria seca não foi influenciada pelo tratamento do grão de milho. Foi observado um efeito linear positivo $(P<0,05)$ na digestibilidade aparente da matéria seca, da matéria orgânica e dos carboidratos totais, em função do aumento do nível de concentrado na dieta. Não é necessária a moagem dos grãos de milho para elaboração de concentrados a serem fornecidos para ovinos.

Palavras-chave: matéria seca, nitrogênio, ruminantes.

\section{ABSTRACT}

In this study corn grain was used as whole, ground or urea treated grain to prepare diet containing 30, 50 or $70 \%$ concentrate. Eighteen castrated lambs (34.48 average body weight) were used during three periods to measure food intake and digestibility. The intake of dry matter (DMI), crude protein (CPI) and neutral detergent fiber (NDFI) were not affected by treatment of corn grain. Level of concentrate in diet affected $(P<0.05)$ DMI and CPI which reached a maximum at 55.5 and $58.7 \%$ concentrate, respectively. The NDFI decreased linearly $(P<0.05)$ with the increasing level of concentrate. Grain treatment did not affected the digestibility of nutrient except for crude protein apparent digestibility which was higher $(P<0.05)$ for diet containing UG. Apparent digestibility of dry and organic matter and total carbohydrates increased linearly with increasing proportion of concentrate in diet. Whole corn grain can be used to prepare concentrate mixtures to be fed to sheep.

Key words: dry matter, nitrogen, ruminant.

\section{INTRODUÇÃO}

A alimentação de ruminantes no Brasil é predominantemente baseada em forragens, a qual fica prejudicada em certos períodos do ano, devido à baixa qualidade e/ou disponibilidade dos pastos, levando a baixos índices de produtividade. Esse fato representa uma deficiência do sistema de produção, visto que, quando se trabalha com ruminantes em altos níveis de produção animal, torna-se necessário o incremento do valor nutritivo das dietas utilizadas na alimentação desses animais. Com esse objetivo, geralmente, são incluídos grãos nas dietas, pois estes possuem grandes quantidades de carboidratos solúveis de fácil digestão, disponibilizando energia metabolizável e de proteína bruta para o desenvolvimento dos animais (THEURER et al., 1999).

\footnotetext{
IAutônomo.

IIDepartamento de Zootecnia, Universidade Federal de Santa Maria (UFSM), Santa Maria, RS, Brasil. E-mail: bonne@ccr.ufsm.br. IIIPrograma de Pós-graduação, Departamento de Zootecnia, UFSM. Rua Lamartine Babo, 750, Camobi, Santa Maria, RS, Brasil, 97105-230. E-mail: pac@mail.ufsm.br. Autor para correspondência.

${ }^{\text {IV }}$ Programa de Pós-graduação em Zootecnia, Universidade Federal do Rio Grande do Sul (UFRGS), Porto Alegre, RS, Brasil.
} 
O amido é um dos principais nutrientes utilizados para promover melhorias na produção de bovinos, sendo que uma das fontes mais usadas para sua obtenção é o grão de milho, que geralmente é fornecido quebrado para os animais. No entanto, a eficaz utilização do amido de grãos é altamente dependente da espécie animal, do tipo e dos métodos de processamento de grãos (THEURER, 1986).

A trituração de cereais para a alimentação dos ruminantes visa a aumentar a área superficial dos grãos para facilitar os processos digestivos, sejam eles fermentativos ou enzimáticos. Todavia, segundo ORSKOV (1990), a conveniência do processamento depende do tipo de grão e do animal. Esse autor afirma que, para ruminantes pequenos, como ovinos, caprinos e bovinos de até $150 \mathrm{~kg}$ de peso vivo, os grãos devem ser fornecidos inteiros, com isto irá ocorrer uma maior mastigação e ruminação, aumentando a produção salivar e diminuindo as oscilações de pH ruminal, não prejudicando a digestão da celulose (VAN SOEST, 1994).

Uma outra forma de fornecimento dos grãos de cereais inteiros é o tratamento com uréia, que além de amenizar os efeitos negativos da menor exposição do amido para as reações digestivas, ainda contribui com uma fonte de nitrogênio não-protéico (NNP) para o desenvolvimento microbiano ruminal.

O ponto ótimo de processamento dos grãos de cereais utilizados na alimentação de ruminantes ainda não está bem definido. O que se sabe é que ocorrem alterações no consumo e na digestibilidade devido ao processamento, ao tipo e à variedade do grão. Quando os níveis de concentrado na dieta são baixos, provavelmente, o processamento dos grãos não tenha efeito nas reações digestivas, mas, quando os níveis são altos, o efeito pode ser mais notado, principalmente na digestibilidade da fibra. Assim, as relações entre os componentes de uma dieta assumem grande importância, repercutindo sobre o padrão de fermentações ruminal e a performance produtiva do animal (MERTENS, 1996).

Este trabalho teve por objetivo avaliar os efeitos da utilização de grãos de milho processados distintamente, em dietas com distintas relações volumoso: concentrado, sobre o consumo e digestibilidade de nutrientes da dieta.

\section{MATERIAL E MÉTODOS}

O experimento foi conduzido no Setor de Nutrição de Ruminantes pertencente ao Departamento de Zootecnia da Universidade Federal de Santa Maria, Santa Maria, RS. Para o ensaio de digestibilidade, foram utilizados dezoito cordeiros cruza Texel x Ideal, com idade e peso vivo médio de 10 meses e 34,48 ^4,93kg, respectivamente.

As dietas foram calculadas segundo recomendações do NRC (1985), para cordeiros pesando $30 \mathrm{~kg}$, com um ganho de peso de $200 \mathrm{~g} \mathrm{dia}^{-1}$. Foram utilizadas as relações 70:30; 50:50 e 30:70 de volumoso:concentrado, na composição das dietas.

O volumoso utilizado foi silagem de sorgo granífero com $46 \%$ de grãos em sua constituição e $\mathrm{pH}$ médio de 4,08. Os concentrados foram compostos por grão de milho processado de diferentes formas, farelo de soja, uréia e minerais. O grão de milho foi utilizado na forma moída (GMM), inteiro (GMI) e inteiro tratado com uréia (GMU). O tratamento do grão de milho com uréia foi realizado na proporção de $2 \%$ da matéria seca do milho, díluida em água para elevar a umidade do milho para 20\%. Após isso, o material tratado foi colocado em recepientes metálicos vedados, com capacidade para 200L, por um período mínimo de 30 dias. A mesma quantidade de uréia, necessária para o tratamento dos grão de milho, foi utilizada na formulação das demais dietas, com o objetivo de equalizar as proporções de nitrogênio não-protéico proveniente da uréia. As composições física e bromatológica das dietas encontram-se nas tabelas 1 e 2 .

Para a determinação do consumo e da digestibilidade in vivo, foram utilizadas gaiolas metabólicas individuais, providas de comedouro, bebedouro, coletor de fezes e urina, onde cada ovino tinha o seu consumo e a sua excreção mensurados. Os alimentos, sobras e excreções foram pesados através de uma balança digital com precisão de $5 \mathrm{~g}$.

O trabalho foi conduzido durante três períodos de 21 dias, subdivididos em três parcelas de sete dias cada, sendo que os sete primeiros dias foram destinados à adaptação dos animais às dietas, do ambiente e à rotina diária de trabalhos. Nos sete dias intermediários, realizou-se o controle do consumo de

Tabela 1 - Composição das dietas de acordo com os diferentes níveis de concentrado.

\begin{tabular}{llll}
\hline & \multicolumn{3}{c}{ Níveis de concentrado (\%) } \\
\cline { 2 - 4 } Componente* (\%) & 30 & 50 & 70 \\
\hline Silagem de sorgo & 69,82 & 49,40 & 29,12 \\
Farelo de soja & 17,70 & 16,00 & 14,28 \\
Grão de milho & 10,50 & 32,00 & 53,55 \\
NaCl & 0,90 & 1,03 & 1,07 \\
Uréia & 0,17 & 0,51 & 0,85 \\
Calcário calcítico & 0,90 & 1,03 & 1,07 \\
Enxofre & 0,01 & 0,03 & 0,06 \\
\hline
\end{tabular}

*Valores expressos com base na matéria seca.

Ciência Rural, v.37, n.1, jan-fev, 2007. 
Tabela 2 - Composição da dieta total em matéria mineral (MM), matéria orgânica (MO), extrato etéreo (EE), protéina bruta (PB), carboidratos totais (CHOT), carboidratos solúveis (CHS), fibra em detergente neutro (FDN) e fibra em detergente ácido (FDA), de acordo com o processamento do grão de milho e com o nível de inclusão de concentrado na dieta

\begin{tabular}{|c|c|c|c|c|c|c|}
\hline \multirow{2}{*}{ Componente* (\%) } & \multicolumn{3}{|c|}{ GMI e GMM } & \multicolumn{3}{|c|}{ GMU } \\
\hline & 30 & 50 & 70 & 30 & 50 & 70 \\
\hline MM & 6,07 & 5,84 & 5,00 & 6,54 & 6,37 & 5,38 \\
\hline MO & 93,93 & 94,17 & 95,00 & 93,46 & 93,64 & 94,62 \\
\hline $\mathrm{EE}$ & 4,35 & 4,64 & 4,34 & 4,09 & 3,81 & 3,87 \\
\hline PB & 13,10 & 13,78 & 13,83 & 13,88 & 14,51 & 15,79 \\
\hline CHOT & 76,94 & 76,08 & 77,03 & 75,94 & 75,65 & 75,15 \\
\hline CHS & 32,03 & 40,07 & 49,61 & 31,49 & 37,66 & 47,33 \\
\hline FDN & 44,92 & 36,01 & 27,42 & 44,60 & 37,99 & 27,82 \\
\hline FDA & 29,58 & 22,94 & 15,87 & 29,89 & 23,24 & 15,85 \\
\hline
\end{tabular}

*Valores expressos com base na matéria seca da dieta total; GMI= grão de milho inteiro, GMM= grão de milho moído e GMU= Grão de milho inteiro com uréia.

alimento, para a determinação do consumo máximo. Os sete dias finais de cada período foram destinados ao período de determinação da digestibilidade, no qual a oferta de alimentos foi de $80 \%$ do consumo máximo, determinado na semana anterior, para evitar ou diminuir a seleção. As fezes foram diariamente coletadas, pesadas, homogeneizadas e amostradas. $\mathrm{O}$ alimento ofertado, as sobras e as fezes foram analisados para a determinação da matéria seca (MS), da matéria mineral (MM), da matéria orgânica (MO), do extrato etéreo (EE) e da proteína bruta (PB), segundo AOAC (1995); da fibra em detergente neutro (FDN) e da fibra em detergente ácido (FDA), de acordo com VAN SOEST et al. (1991) e dos carboidratos totais (CHOT) e dos carboidratos solúveis (CHS), de acordo com SNIFFEN et al. (1992).

O cálculo da digestibilidade aparente de nutrientes procedeu-se através da diferença entre o consumido e o excretado, de acordo com o proposto por MERCHEN (1988):

Digest $(\%)=$ Nutriente consumido (g/dia) - Nutriente excretados nas fezes (g/dia) $\times 100$

Nutriente consumido (g/dia)

O delineamento experimental foi 0 inteiramente casualizado, em um arranjo fatorial $3 \times 3$, (três processamentos do grão de milho e três níveis de concentrado), com seis repetições. Os dados foram submetidos à análise de variância, e às médias foi aplicado o Teste Tukey ao nível de 5\% de significância. Foram ajustadas equações de regressão considerando como variável independente o nível de inclusão de concentrado na dieta. As análises estatísticas foram realizadas através do programa SAS (1996).

\section{RESULTADOS E DISCUSSÃO}

Não houve efeito da interação $(\mathrm{P}>0,05)$ entre o processamento do grão de milho e os níveis de inclusão de concentrado na dieta sobre o peso vivo final (PV), o consumo de matéria seca (CMS), o consumo de proteína bruta (CPB) e consumo de fibra em detergente neutro (CFDN), cujos valores médios obtidos em relação aos processamentos do grão de milho, assim como as referidas médias e equações de regressão obtidas em função dos níveis de inclusão de concentrado na dieta, encontram-se na tabela 3 .

Não houve efeito $(\mathrm{P}>0,05)$ do processamento do grão de milho nem do nível de inclusão de concentrado sobre o PV dos animais, assim como não foram observadas diferenças $(\mathrm{P}>0,05)$ entre os processamentos do grão de milho para CMS, CPB e CFDN. Entretanto, verificou-se um efeito quadrático com pontos de máximo consumo em 55,5 e 58,8\% de concentrado na dieta para CMS e CPB $(\mathrm{P}<0,05$ e $\mathrm{P}<0,01)$, respectivamente. O CFDN comportou-se de forma linear decrescente $(\mathrm{P}<0,01)$, de acordo com o nível de inclusão de concentrado, o que pode ser explicado pela menor concentração de FDN nas dietas mais concentradas. Todavia, a interpretação desses resultados requer certa cautela, em virtude dos baixos valores obtidos para os coeficientes de determinação.

Os valores médios de CMS e CPB foram de $1,112 \pm 0,211 \mathrm{~kg} \mathrm{dia}{ }^{-1}$ e $0,152 \pm 0,033 \mathrm{~kg} \mathrm{dia}^{-1}$, respectivamente, estando de acordo com o NRC (1985), o qual propõe um CMS de $1,100 \mathrm{~kg} \mathrm{dia}^{-1}$ e de $0,160 \mathrm{~kg}$ $\mathrm{dia}^{-1}$ de CPB para esta categoria de ovinos.

Esperava-se que os animais alimentados com dietas com milho moído consumissem mais matéria seca, devido à menor granulometria da dieta e 
Tabela 3 - Valores médios e equações de regressão para peso vivo final (PV), consumo de matéria seca (CMS), consumo de proteína bruta (CPB) e consumo de fibra em detergente neutro (CFDN), de acordo com o processamento do grão de milho e o nível de inclusão de concentrado na dieta.

\begin{tabular}{|c|c|c|c|c|c|c|}
\hline \multirow{2}{*}{ Variável } & \multicolumn{3}{|c|}{ Processamento do milho* } & \multicolumn{3}{|c|}{ Nível de concentrado** } \\
\hline & GMM & GMI & GMU & 30 & 50 & 70 \\
\hline $\mathrm{PV}^{1}(\mathrm{~kg})$ & 33,743 & 35,242 & 34,329 & 33,00 & 36,29 & 34,13 \\
\hline $\mathrm{CMS}^{2}\left(\mathrm{~kg} \mathrm{dia}^{-1}\right)$ & 1,108 & 1,092 & 1,138 & 1,015 & 1,193 & 1,130 \\
\hline $\mathrm{CPB}^{3}\left(\mathrm{~kg} \mathrm{dia}^{-1}\right)$ & 0,145 & 0,145 & 0,164 & 0,132 & 0,163 & 0,161 \\
\hline $\mathrm{CFDN}^{4}\left(\mathrm{~kg} \mathrm{dia}^{-1}\right)$ & 0,389 & 0,394 & 0,425 & 0,458 & 0,435 & 0,311 \\
\hline
\end{tabular}

*Não houve diferença pelo Teste Tukey $(\mathrm{P}>0,05)$; GMM= milho moído, GMI= milho inteiro e GMU= milho inteiro tratado com uréia; ** analisado por regressão $\left({ }^{1,2,3,4}\right)$; ns= não-significativo; $\mathrm{NC}=$ nível de concentrado; $\mathrm{CV}=$ coeficiente de variação; $\mathrm{R}^{2}=$ coeficiente de determinação; $\mathrm{P}=$ significância.

${ }^{1} \mathrm{y}=34,47 \mathrm{~ns}$

${ }^{2} \mathrm{y}=0,303+0,033 \mathrm{NC}-0,0003 \mathrm{NC}^{2}\left(\mathrm{CV}=18,18 ; \mathrm{R}^{2}=12,13 ; \mathrm{P}<0,05\right)$.

${ }^{3} \mathrm{y}=0,0262+0,0047 \mathrm{NC}-0,00004 \mathrm{NC}^{2}\left(\mathrm{CV}=20,30 ; \mathrm{R}^{2}=17,99 ; \mathrm{P}<0,01\right)$

${ }^{4} \mathrm{y}=0,584-0,0037 \mathrm{NC}\left(\mathrm{CV}=20,71 ; \mathrm{R}^{2}=34,51 ; \mathrm{P}<0,01\right)$.

conseqüente maior taxa de passagem do alimento pelo trato gastrintestinal, que os animais alimentados com grãos de milho inteiro e inteiro tratado com uréia. Isso não ocorreu, provavelmente, devido ao processo mastigatório dos ovinos ser bastante eficiente, fazendo com que os grãos inteiros consumidos fossem reduzidos, já na ingestão, a partículas pequenas semelhantes às dos grãos moídos (MCDONALD et al., 1981).

Em um trabalho conduzido com cordeiras, HEJAZI et al. (1999) encontraram valores de CMS semelhantes aos determinados neste trabalho, assim como não encontraram diferenças significativas no CMS em função de diferentes processamentos do grão de milho. BETT et al. (1999) não observaram diferenças para CMS de cordeiros alimentados com grão de canola integral, quebrado ou peletizado. O CPB e CFDN obtidos no presente estudo foram inferiores aos encontrado por BETT et al. (1999), o que pode ser explicado pela maior concentração protéica e de FDN nas dietas utilizadas pelo referido autor. Trabalhando com bovinos, ALCADE et al. (2000) não encontraram diferenças no CMS quando alimentaram os animais com grão de milho inteiro ou moído grosso. Da mesma forma, VARGAS JR. (2000) também não encontrou diferenças no CMS, quando alimentou novilhos com grão de milho moído, inteiro ou inteiro tratado com uréia.

A variação do CMS, em função dos níveis de concentrado na dieta, indica haver uma limitação física ruminal provocada pelos tratamentos com baixo teor de concentrado, ocorrendo uma menor e mais lenta digestão do volumoso em relação ao concentrado. $\mathrm{O}$ enchimento e a distenção ruminal provocam estímulos neurais inibitórios, reduzindo a ingestão de alimentos
(GROVUM, 1988). Por outro lado, a redução observada no CMS para níveis maiores que $55,5 \%$ de concentrado na dieta pode ser explicada por uma possível limitação química ou metabólica, provocada pela alta concentração energética destas dietas. De acordo com VAN SOEST (1994), dietas muito concentradas proporcionam uma elevada produção de ácidos graxos voláteis, bem como provocam uma modificação na relação acetato:propionato, alterando as condições do ambiente ruminal. Nessas situações, ocorre uma redução do $\mathrm{pH}$ ruminal e um aumento da concentração de metabólitos sangüíneos, determinando uma resposta através do sistema humoral, inibindo o CMS. Outro fator que pode alterar o consumo de matéria seca é a disponibilidade de energia em relação à proteína, influenciando sobre a atividade dos microorganismos ruminais. Foi observado um comportamento quadrático do CMS, em função do nível de inclusão de concentrado na dieta.

Os resultados de digestibilidade aparente dos componentes do alimento obtidos no presente estudo estão demonstrados na tabela 4. Não houve interação $(P>0,05)$ entre processamento do grão de milho e nível de inclusão de concentrado na dieta para digestibilidade aparente da matéria seca (DMS), da matéria orgânica (DMO), da proteína bruta (DPB), do extrato etéreo (DEE), dos carboidratos totais (DCHOT), dos carboidratos solúveis (DCHOS), da fibra em detergente neutro (DFDN) e da fibra em detergente ácido (DFDA). Pode-se observar que ocorreu uma maior $(\mathrm{P}<0,05) \mathrm{DPB}$ para a dieta que continha grão de milho inteiro tratado com uréia. Tal fato era esperado e pode ser explicado pela retenção de nitrogênio proveniente da uréia, no grão de milho tratado, uma vez que este nitrogênio, na forma não-protéica, deve ser prontamente hidrolisado no rúmen dos animais. 
Tabela 4 - Valores médios e equações de regressão para digestibilidade aparente da matéria seca (DMS), da matéria orgânica (DMO), da proteína bruta (DPB), do extrato etéreo (DEE), dos carboidratos totais (DCHOT), dos carboidratos solúveis (DCHOS), da fibra em detergente neutro (DFDN) e da fibra em detergente ácido (DFDA), de acordo com o processamento do grão de milho e com o nível de inclusão de concentrado na dieta.

\begin{tabular}{|c|c|c|c|c|c|c|}
\hline \multirow{2}{*}{ Variável (\%) } & \multicolumn{3}{|c|}{ Processamento do milho* } & \multicolumn{3}{|c|}{ Nível de concentrado** } \\
\hline & GMM & GMI & GMU & 30 & 50 & 70 \\
\hline $\mathrm{DMS}^{1}$ & 67,68 & 67,78 & 71,10 & 63,64 & 69,14 & 73,77 \\
\hline $\mathrm{DMO}^{2}$ & 69,24 & 69,55 & 72,28 & 64,85 & 70,92 & 75,31 \\
\hline $\mathrm{DPB}^{3}$ & $67,52^{b}$ & $65,95^{\mathrm{b}}$ & $72,34^{\mathrm{a}}$ & 67,05 & 69,50 & 69,27 \\
\hline $\mathrm{DEE}^{4}$ & 71,98 & 71,96 & 71,07 & 71,99 & 72,91 & 70,11 \\
\hline DCHOT $^{5}$ & 71,47 & 68,86 & 72,22 & 66,35 & 70,92 & 75,28 \\
\hline $\mathrm{DCHS}^{6}$ & 88,04 & 89,09 & 89,61 & 86,92 & 90,39 & 89,42 \\
\hline $\mathrm{DFDN}^{7}$ & 46,61 & 46,92 & 51,96 & 49,48 & 49,09 & 46,91 \\
\hline DFDA $^{8}$ & 31,24 & 27,80 & 34,78 & 31,43 & 32,20 & 30,20 \\
\hline
\end{tabular}

*a, b na linha indicam diferença $(\mathrm{P}<0,05)$ pelo Teste de Tukey; GMM= milho moído; GMI= milho inteiro e GMU= milho inteiro tratado com uréia; **analisado por regressão $\left({ }^{1,2,3,4,5,6,7,8}\right)$; ns= não significativo; $\mathrm{NC}=$ nível de concentrado; $\mathrm{CV}=$ coeficiente de variação; $\mathrm{R}^{2}=$ coeficiente de determinação; $\mathrm{P}=$ significância.

${ }^{1} \mathrm{y}=56,21+0,25 \mathrm{NC}\left(\mathrm{CV}=6,69 ; \mathrm{R}^{2}=44,84 ; \mathrm{P}<0,01\right)$.

${ }^{2} \mathrm{y}=57,27+0,26 \mathrm{NC}\left(\mathrm{CV}=6,93 ; \mathrm{R}^{2}=43,77 ; \mathrm{P}<0,01\right)$.

${ }^{3} \mathrm{y}=68,61 \mathrm{~ns}$

${ }^{4} \mathrm{y}=71,67 \mathrm{~ns}$

${ }^{5} \mathrm{y}=59,41+0,23 \mathrm{NC}\left(\mathrm{CV}=8,28 ; \mathrm{R}^{2}=28,70 ; \mathrm{P}<0,01\right)$.

${ }^{6} \mathrm{y}=88,91 \mathrm{~ns}$.

${ }^{7} \mathrm{y}=48,76 \mathrm{~ns}$

${ }^{8} \mathrm{y}=31,28 \mathrm{~ns}$.

Os valores expressos na tabela 4 demonstram a ocorrência de um comportamento linear positivo $(\mathrm{P}<0,01)$ nas DMS, DMO e DCHOT, de acordo com a inclusão de concentrado na dieta, o que já era esperado. Isto pode ser explicado pela maior digestibilidade do concentrado em comparação com o volumoso, sendo que as dietas com maior proporção de concentrado apresentaram menor consumo de FDN, ficando menos fibrosas e lignificadas. Outro aspecto a ser destacado é que a composição dos carboidratos totais (CHOT), nos tratamentos com maior nível de concentrado, contempla uma maior quantidade de carboidratos solúveis, determinando uma maior digestibilidade desta fração.

Em um estudo realizado com bovinos, VARGAS JR. (2000) observou uma maior DMS quando alimentou os animais com uma dieta contendo grão de milho inteiro tratado com uréia. Todavia, os valores de DMS encontrados pelo referido autor foram inferiores aos observados neste trabalho. Já TURGEON et al. (1983) não encontraram diferenças na DMS de dietas contendo grãos de milho processado de diferentes formas e utilizados na alimentação de bovinos. Da mesma forma, em um estudo conduzido com ovinos, HART \& GLIMP (1991) não observaram diferenças na digestibilidade da matéria seca, na digestibilidade do amido e na digestibilidade da proteína de dietas elaboradas com milho inteiro ou com milho moído peletizado. Assim, destaca-se a relevância deste tipo de estudo na busca de informações que possibilitem o avanço de conhecimentos nesta área da nutrição de ruminantes.

\section{CONCLUSÕES}

Não é necessária a moagem dos grãos de milho quando este for incluído na formulação de concentrados a serem fornecidos para ovinos. O consumo de matéria seca apresenta um comportamento quadrático em função do nível de inclusão de concentrado na dieta.

\section{REFERÊNCIAS}

ALCALDE, C.R. et al. Avaliação dos milhos inteiros, moídos e da sua mistura no desempenho de novilhos em confinamento. In: REUNIÃO ANUAL DA SOCIEDADE BRASILEIRA DE ZOOTECNIA, 37., 2000, Viçosa, MG. Anais... Viçosa: SBZ, 2000. p.346.

ASSOCIATION OF OFFICIAL ANALYTICAL CHEMISTS Official methods of analysis. 12.ed. Washington, DC., 1995. 1298p.

BETT, V. et al. Desempenho e digestibilidade in vivo de cordeiros alimentados com dietas contendo canola em grão integral em diferentes formas. Revista Brasileira de Zootecnia, v.28, n.4, p.808-815, 1999. 
GROVUM, W.L. Apetito, sapidez y control del consumo de alimentos. In: CHURCH, D.C. El rumiante. Fisiología digestiva y nutrición. Zaragoza: Acribia, 1988. Cap.10, p.225-242.

HART, S.P.; GLIMP, H.A. Effect of diet composition and feed intake level on diet digestibility and ruminal metabolism in growing lambs. Journal Animal Science, v.69, p.1636$1644,1991$.

HEJAZI, S. et al. Effects of corn processing and dietary fibber source on feedlot performance, visceral organ weight, diet digestibility, and nitrogen metabolism in lambs. Journal Animal Science, v.77, p.507-515, 1999.

MCDONALD, P. et al. Animal nutrition. 3.ed. Zaragoza: Acribia, 1981. 518p.

MERCHEN, N.R. Digestión, absorción y excreción en los rumiantes. In: CHURCH, D.C. El rumiante. Fisiología digestiva y nutrición. Zaragoza: Acríbia, 1988. Cap.9, p.191224.

MERTENS, D.R. Using fiber and carbohydrate analyses to formulate dairy rations. In: INFORMATIONAL CONFERENCE WITH DAIRY AND FORAGES INDUSTRIES, 1996, Wisconsin. Proceedings... Wisconsin: Us Dairy Forage Research Center, 1996. p.81-92.

NATIONAL RESEARCH COUNCIL. Nutrients requirements of sheep. 6.ed. Washington, DC., 1985. 242p.

ORSKOV, E.R. Alimentación de los rumiantes: principios e práctico. Zaragoza: Acríbia, 1990. 119p.
Statistical Analysis System. Software, Version 6.11. Cary: SAS Institute, 1996. CD-Rom.

SNIFFEN, C.J. et al. A net carbohydrate and protein system for evaluating cattle diets: II. Carbohydrate and protein availability. Journal Animal Science, v.70, n.3, p.3562-3577, 1992

THEURER, C.B. et al. Invited review: summary of steamflaking corn or sorghum grain for lactating dairy cows. Journal Dairy Science, v.82, p.1950-1959, 1999.

THEURER, C.B. Grain processing effects on starch utilization by ruminants. Journal Animal Science, v.63, p.1649-1662, 1986.

TURGEON, O.A. et al. Corn particle size mixtures, roughage level and starch utilization in finishing steer diets. Journal Animal Science, v.57, n.3, p.739-749, 1983.

VAN SOEST, P.J. Nutritional ecology of the ruminant. 2.ed. Ithaca: Cornel University, 1994. 476p.

VAN SOEST, P.J. et al. Methods for dietary fiber, neutral detergent fiber and nonstarch polysaccharide in relation to animal nutrition. Journal of Dairy Science, v.74, p.35833597, 1991.

VARGAS JR., F.M. Consumo, digestibilidade, desempenho e parâmetros ruminais em terneiros alimentados com dietas contendo grão de milho inteiro, moído ou tratado com uréia. 2000. 102f. Dissertação (Mestrado em Zootecnia) - Universidade Federal de Santa Maria, departamento de Zootecnia. 